\title{
Evolução da cobertura vegetal e uso agrícola do solo no município de Lagoa Seca, PB ${ }^{1}$
}

\author{
$\overline{\text { Íris do S. Barbosa }{ }^{2} \text {, Leonaldo A. de Andrade }{ }^{3} \text { \& José A. P. de Almeida }}{ }^{4}$
}

\begin{abstract}
RESUMO
O presente estudo consiste no levantamento de informações relacionadas aos aspectos biofísicos, mapeamento e quantificação da vegetação natural e das áreas agricultáveis, mediante interpretação de fotos aéreas de 1984, análise visual de imagem digital do satélite Landsat, canais TM3, TM4 e TM5, datada de 10 de julho de 1989 e no levantamento de coordenadas através do Sistema de Posicionamento Global (GPS), 2001. Foram elaborados, para a área em estudo, arquivos digitais georreferenciados, referentes aos temas limite municipal, cobertura vegetal natural e uso agrícola do solo, em ambos os períodos, 1984 e 2001, utilizados para a classificação da vegetação secundária dominante, na circunscrição das áreas de uso agrícola, de acordo com a prática agrícola peculiar, na identificação das fisionomias vegetais e avaliação do processo evolutivo das fisionomias no período mencionado.
\end{abstract}

Palavras-chave: sensoriamento remoto, mapeamento, vegetação

\section{Evolution of vegetation covering and land use in the municipal district of Lagoa Seca, PB}

\begin{abstract}
This study comprised of the collection of data on biophysical aspects, the mapping and quantification of natural vegetation and arable areas, through interpretation of aerial pictures taken in 1984, visual analysis of digital images from Landsat satellites, TM3, TM4 and TM5 channels, carried out on July 10, 1989 and the survey of coordinates through the Global Positioning System (GPS), 2001. Digital geo-referenced files elaborated for the studied area comprising basic data about the municipal limit, natural vegetation covering, land use, in both periods, 1984 and 2001, were used for classification of the dominant secondary vegetation, definition of the agricultural use of soil in agreement with the peculiar agricultural practices, identification of the vegetable physiognomies and evaluation of their evolutionary process in the mentioned period.
\end{abstract}

Key words: remote sensing, mapping, vegetation

\footnotetext{
1 Parte da Dissertação de Mestrado do primeiro autor, realizada com apoio da Capes

2 Centro Acadêmico do Agreste/UFPE. CEP 36571-000. Caruaru, PE. Fone: (81) 3727-6793. E-mail: irisbarbosa@ufpe.br

3 Departamento de Fitotecnia/UFPB, CEP 58397-000, Areia, PB. Fone: (83) 3362-2300. E-mail: landrade@cca.ufpb.br

${ }^{4}$ Departamento de Geografia/UFS, CEP 49100-000, Aracaju, SE. Fone: (79) 3212-6742. E-mail: jalmeida@ufs.br
} 


\section{INTRODUÇÃO}

A expressão uso da terra, segundo Pacheco \& Ribas (1998), pode ser entendida como sendo a forma pela qual o espaço está sendo ocupado pelo homem. O levantamento do uso da terra é de grande importância, na medida em que os efeitos do uso desordenado causam deterioração no ambiente; sendo assim, o levantamento do uso da terra em uma região, tornouse aspecto fundamental para a compreensão dos padrões de organização do espaço; existe, deste modo, a necessidade de atualização constante dos registros de uso do solo para que suas tendências possam ser analisadas (Rosa, 1992).

Neste contexto, o sensoriamento remoto se constitui em uma técnica de grande utilidade, pois permite, em curto espaço de tempo, a obtenção de grande quantidade de informações a respeito de registros de uso da terra. O levantamento do uso da terra em dada região tornou-se um aspecto de interesse fundamental para a compreensão dos padrões de organização do espaço, Santos et al. (1981).

Ainda segundo Pacheco \& Ribas (1998), medidas para o planejamento do uso da terra têm sido, até recentemente, baseadas em informações fragmentadas sobre os efeitos do uso do solo no ambiente, o que se deve à ausência de registros seguros sobre as condições de uso da terra não se podendo, daí, avaliar as alterações que são provocadas pelo homem.

Fator importante na manutenção dos recursos naturais renováveis, a cobertura vegetal exerce função essencial na manutenção do ciclo da água, protegendo o solo contra o impacto das gotas de chuva aumentando a porosidade e a permeabilidade pela ação das raízes, proporcionando a manutenção da umidade e a fertilidade do solo (Bertoni \& Lombardi Neto, 1985).

Freitas Filho \& Medeiros (1993), realizaram uma análise multitemporal da cobertura vegetal em parte da chapada do Araripe,CE, no período de 1987-1990, utilizando fotografias aéreas pancromáticas e imagem do satélite TM/Landsat5 e observaram que em 1990, a cobertura vegetal foi reduzida em 19\%, sendo atribuído à intensa ação antrópica; os autores concluíram, ainda, que as técnicas de sensoriamento remoto apresentam comprovado nível de eficiência em atividades voltadas para os recursos naturais.

Neste mesmo sentido, Guimarães (1999) com base na compreensão circunstanciada das interações dinâmicas existentes entre os sistemas ecológicos e os sistemas agrossocioeconômicos, desenvolveu um estudo buscando integrar e estruturar uma base cartográfica digital com acesso remoto a dados essenciais e multilocais, para uma caracterização simultânea dos sistemas ecológicos e socioeconômicos em escala regional, para a região de Vitória da Conquista, BA.

Segundo Santos \& Martins (2001) os estudos sobre uso das terras necessitam estar baseados em um entendimento circunstanciado das interações dinâmicas existentes no meio ambiente para subsidiar uma política de ordenamento territorial, visando conciliar recuperação, preservação com produção e adequação da legislação ambiental.

O mapeamento digital é uma ferramenta de extrema importância no planejamento territorial e ambiental, servindo como subsídio À elaboração de produtos cartográficos. Segundo Estes \& Mooneyhan (1994) os documentos cartográficos em diferentes escalas são ferramentas fundamentais para se conhecer o meio ambiente em escala local, regional e global e ajuda na tomada de decisões necessárias para o planejamento ambiental e o gerenciamento de recursos.

$\mathrm{O}$ tratamento digital de dados espaciais como subsídio à análise dos aspectos da paisagem, tem sido muito utilizado em estudos acadêmicos e institucionais de diagnósticos, mapeamentos e zoneamentos ambientais; atualmente, a utilização de alguns softwares com resolução gráfica constitui ferramenta de trabalho muito usada para a elaboração de mapas temáticos.

Os sistemas do tipo Computer Adviser Design (CAD), permitem a conversão de dados analógico-digitais e, associados ao Sistema de Gerenciadores de Banco de Dados (SGBD), possibilitam a elaboração de mapas digitais conjugando informações gráficas e não gráficas e, em geral, estão acoplados aos Sistemas de Informações Geográficas (SIGs), fazendo interface e auxiliando a execução de mapeamentos temáticos (Argento, 1995). Face a isso, este trabalho teve por objetivo a produção de dois mapas de uso do solo e cobertura vegetal natural, digitalizados, sendo o primeiro com dados de 1984, e o segundo de 2001; a partir desses mapas, pôde-se quantificar e estudar a evolução do uso no período entre 1984 e 2001. Pretendeu-se também, caracterizar os padrões das fisionomias presentes, a fim de subsidiar possíveis trabalhos de planejamento do uso e manejo agrícola do solo, assim como ações conservacionistas dos recursos naturais e renováveis no município, em detrimento do fato de que esta região está sendo alterada muito rapidamente devido à ação antrópica

\section{MATERIAL E MÉTODOS}

\section{Materiais e procedimentos metodológicos para elaboração dos mapas temáticos \\ Na primeira fase desse estudo, fez-se a fotointerpretação} das fotografias aéreas, Obra $473(\mathrm{Fx} 4, \mathrm{n} .5-9$, Fx5, n.4-10, Fx6, n.5-9) na escala de 1:30.000, FUNDAP (1984) elaborando-se cópias das imagens fotografias em papel vegetal (overlays); já a segunda fase consiste na utilização de imagens orbitais TM/Landsat-5 nas bandas 3, 4 e 5 e composição colorida 3B/4G/5R, na escala 1:100.000. O software SPRING 3.0 (Sistema de Processamento de Imagens Georreferenciadas), INPE (1998) foi a ferramenta utilizada para processar a imagem, possibilitando a definição dos contornos das áreas com cobertura vegetal natural e de uso agrícola no município em 1989.

A carta topográfica SB-25-Y-C-I, folha Campina Grande, escala 1:100.000 SUDENE (1999), subsidia o posicionamento de pontos em coordenadas UTM e o GPS - Geographic Position System permite a tomada das coordenadas geográficas objetivando o georreferrenciamento das áreas correspondentes à cobertura vegetal natural e uso do solo em 2001, evidenciados nos mapas digitalizados no Autocad 2000, sistema do tipo Computer Adviser Design (CAD). 


\section{Processamento e análise das imagens}

Realizou-se, para esta etapa, um pré-processamento, através da aplicação da técnica de realce e a classificação para análise das imagens utilizando-se, para esses procedimentos, o SPRING 3.0.

As informações, provenientes da análise por verossimilhança das imagens digitais do sensor TM/Landsat-5 através da importação da imagem tipo TIF para módulo IMPIMA do SPRING 3.0, INPE (1998) e da carta topográfica, Folhas SC 24-25 Aracaju/Recife, Brasil (1983), utilizada para estabelecer as coordenadas limítrofes do município, foram coadunadas para se obter as informações recentes da cobertura vegetal e uso agrícola do solo, referentes ao ano de 2001.

A utilização da imagem TM/Landsat-5 foi essencial em virtude da ausência de informações da situação leste do município pela inexistência de cobertura fotográfica da área.

Paralelamente ao processo citado se definiram os elementos passíveis de serem extraídos das fotografias aéreas: estradas, rios, espaços urbanizados e os estratos da cobertura vegetal, cujo procedimento permitiu a acuracidade de interpretação da vegetação e do uso agrícola dos solos, em 1984, e posterior elaboração dos mapas-base a partir das informações contidas nos overlays.

Dando seqüência ao processo, realizou-se a segunda etapa, que consistiu na definição das coordenadas UTM (Universal Transverso de Mercator) limítrofes do município, nas ortofotocartas copiadas, que serviram de apoio para que as informações geradas estivessem referenciadas geograficamente segundo um sistema de projeção, que possibilitasse a referenciação e a digitalização utilizando o Software Autocad 2000 e mesa digitalizadora tamanho A0; a segunda fase do estudo consistiu no processamento da imagem digital TM/Landsat-5, canais TM3, TM4 e TM5, datada de 10 de julho de 1989, utilizando-se a classificação supervisionada com o auxílio do software SPRING 3.0; após a leitura e gravação das imagens de satélite, procedeu-se ao georreferenciamento da imagem através das coordenadas definidas carta topográfica SB-25-Y-C-I, folha Campina Grande, escala 1:100.000, consistindo no posicionamento de pontos em coordenadas UTM.

A retificação da imagem apresenta precisão de 15 x 15 m e o mosaico elaborado por intermédio das imagens geograficamente retificadas possui um deslocamento médio de um pixel, o que é aceitável na realização desse tipo de trabalho considerado, por Crosta (1992), um registro adequado para imagens de satélite, pois apresenta resolução abaixo de um pixel.

Uma vez feito o tratamento da imagem com a composição colorida 4 (vermelho), 5 (verde) e 3 (azul), submeteu-se a imagem ao tratamento de realce de contrastes e se fez a equalização para melhor identificação e agrupamento dos aspectos referentes à cobertura vegetal e ao uso agrícola do solo.

Devidamente eqüalizada, a imagem passou pelo processo de classificação automática supervisionada pelo método MAXVER (máxima verossimilhança) conforme Ribeiro \& Centeno (2001), com o mínimo de dez amostras por classe. $\mathrm{Na}$ análise da matriz de classificação admitiram-se ape- nas os valores próximos a $100 \%$, e se eliminaram as amostras que apresentaram alto percentual de outra classe de vegetação.

Fez-se, com o intuito de uniformizar os temas, a reclassificação da imagem eliminando-se os pontos isolados, classificados diferentemente de sua vizinhança; este tratamento permitiu a melhor visualização das feições mais específicas de difícil identificação nas imagens.

A escolha dos canais TM3, TM4 e TM5 se justifica através das suas propriedades, adequadas ao estudo da paisagem; a imagem classificada foi impressa e utilizada para averiguação da ocorrência das suas fisionomias, durante o levantamento a campo, para atualização dos dados.

De acordo com o sensor TM (Thematic Mapper) o canal TM3 corresponde à banda vermelha $(0,62$ a $0,69 \mu)$ que ressalta os vegetais, visto que a clorofila dos vegetais absorve as radiações vermelhas. O canal TM4 se refere à banda infravermelho próximo $(0,78$ a $0,90 \mu)$, que ressalta, também, os vegetais que refletem e não absorvem as radiações infravermelhas e as superfícies minerais, que se comportam inversamente aos vegetais enquanto o canal TM5 correspondente à banda infravermelho médio $(1,57$ a $1,78 \mu)$ e coloca em destaque o teor de água, dos solos e dos vegetais.

O tratamento digital da imagem viabilizou o processo de interpretação e análise visual do uso e ocupação do solo; essas informações digitalizadas permitiram a complementação das informações já obtidas através das fotos aéreas e ortofotocartas, em que os dados se apresentam incompletos, pois o vôo realizado em 1984 pela FUNDAP/Terrafoto não cobriu toda a área do município.

A terceira fase deste estudo consistiu em se utilizar o GPS - Geographic Position System para tomada das coordenadas geográficas objetivando-se o georreferrenciamento das informações atualizadas que constam no mapa de vegetação e uso agrícola do solo de 2001.

Os dados produzidos segundo levantamento a campo, foram convenientemente associado às informações retiradas do mapeamento da cobertura florestal nativa lenhosa do Estado da Paraíba, realizado por Lins \& Medeiros (1994) da classificação ecológica da Paraíba, executada por Andrade (1995), do estudo do uso do solo e da vegetação atual também deste Estado, realizado por Melo (1985) e do estudo botânico do Nordeste realizado por von Luetzelburg (1923). Utilizaram-se, para a classificação da vegetação natural, as orientações do Sistema de Classificação Fitogeográfica sugerido pelo Manual técnico da vegetação brasileira, FIBGE (1992).

Os mapas com informações sobre a cobertura vegetal e uso do solo agrícola dos anos de 1984 e 2001, foram digitalizados em Autocad 2000; neles estão devidamente individualizadas as áreas com os tipos de cobertura vegetal e uso do solo segundo as orientações para a classificação da vegetação natural sugerida pelo Sistema de Classificação Fitogeográfica, FIBGE (1992) e o Sistema de Classificação de Uso da Terra (FIBGE, 1999).

Em termos de cartografia ecológica, o estudo resultou na produção dos mapas temáticos da vegetação natural e uso agrícola do solo de 1984 e 2001, os quais foram utilizados 
para avaliação do processo evolutivo das fisionomias no referido período, resultando na classificação da vegetação secundária dominante, na circunscrição das áreas de uso agrícola, de acordo com a prática agrícola peculiar, na identificação das fisionomias vegetais e na regularidade da estrutura dessas fisionomias.

As fisionomias estão classificadas e descritas por tipo e correspondem a:

a) Tipo 1: Vegetação secundária tipo capoeirinha, com predomínio de plantas herbáceas. Caracterizada pela ocorrência de plantas herbáceas, predominantemente anuais ou bianuais, associadas às plantas semi-lenhosas, em menor proporção; é a vegetação típica dos primeiros estágios sucessionais dos campos abandonados, genericamente denominada capoeirinha, correspondendo à segunda fase do Sistema Secundário; Pastagens naturais ou plantadas - campos naturais de gramíneas e áreas submetidas a erradicações de vegetação natural e implantadas espécies de gramíneas

b) Tipo 2: Vegetação secundária classificada como capoeira rala e capoeira. A capoeira rala é o estágio sucessional cuja fisionomia apresenta um misto de espécies, poucas herbáceas e muitas sublenhosas, de médio porte e lenhosas, caracterizando-se como arbustivo-arbórea, agregadas a capoeira, fisionomia em que a fase sucessional é caracterizada por associação complexa de espécies lenhosas com característica arbóreo-arbustiva; correspondem, respectivamente, às terceira e quarta fases.

c) Tipo 3: Vegetação secundária tipo capoeirão. Fisionomia caracterizada por vegetação secundária eminentemente lenhosa, alta, perenifólia, com algumas espécies caducifólias, com características de fragmentos de floresta nativa, constituindo-se no capoeirão; corresponde à quinta fase do Sistema Secundário.

d) Tipo 4: Agricultura de transição com culturas permanentes, predominando a fruticultura. Áreas agrícolas com predominância do cultivo de frutíferas através de uma agricultura com que se obtém o fornecimento de um ou mais fatores de produção não tradicional lucrativo.

e) Tipo 5: Agricultura de transição com culturas permanentes, com predomínio de cultivo de olerícolas. Áreas agrícolas onde há intensa prática do cultivo de olerícolas através de uma agricultura com a qual se obtém o fornecimento de um ou mais fatores de produção não tradicional lucrativo.

f) Tipo 6: Agricultura de transição com predomínio de culturas cíclicas. Agricultura praticada por pequenos e médios produtores; utiliza práticas modernizadas, sempre que é possível. As relações sociais de produção são familiares e assalariadas, nas ocasiões de maior trabalho com a cultura, caracteristicamente cultivos anuais e bianuais.

g) Tipo 7: Agricultura de subsistência. Caracterizadas por serem áreas utilizadas para atividades agrícolas, praticadas apenas com a finalidade de subsistência do produtor; só o excedente da produção é comercializado; o valor do bem é utilizado para a aquisição de outros produtos essenciais à sobrevivência da família. Dá-se, com predominância, o cultivo de feijão, milho, mandioca etc salientando-se, portanto, a policultura.

\section{Leitura e análise da imagem de satélite}

A leitura da imagem deu asas à definição dos aspectos físicos, como solo nu, afloramentos rochosos e da rede de drenagem, de todo o município, o que permitiu a complementação das informações essenciais à delimitação do município, análise da vegetação e uso agrícola do solo, informações estas ausentes nas fotografias aéreas quanto à parte mais oriental do município.

Os critérios do sistema de classificação fitogeográfica para vegetação natural, FIBGE (1992) se baseiam no porte e densidade da vegetação e os do uso do solo, no tipo de exploração agrícola em uso.

A caracterização obtida após classificação supervisionada da imagem de satélite, como informação mais recente, contribuiu para a identificação das áreas com possível presença de remanescentes de vegetação nativa, auxiliando nos levantamentos de dados no campo. Por outro lado, manchas de vegetação natural mais densas do tipo remanescente florestal ou capoeirão foram salientadas a cobertura arbóreoarbustiva do tipo capoeira e de forma mais difusa, a arbustiva-arbórea, do tipo capoeira rala.

A vegetação herbácea, aqui denominada capoeirinha, na referida imagem se confunde com o revestimento vegetal das áreas cultivadas, formando manchas difusas; este tipo de vegetação foi melhor salientado através da FUNDAP (1984).

As informações supracitadas coadunadas com os levantamentos procedidos, a campo, revelam que muitas dessas áreas foram desmatadas; em alguns casos a vegetação natural foi substituída por pastagem ou culturas agrícolas constatando-se, somente em áreas restritas, a ocorrência de regeneração da vegetação secundária classificada como capoeira e capoeira que, atualmente aparecem em forma de pequenas ilhas.

Este aspecto comum ao estádio dos remanescentes da cobertura vegetal natural é, atualmente, encontrado em todo o município, sobretudo nas situações mais úmidas e de difícil acesso.

\section{RESULTADOS E DISCUSSÃO}

A área analisada corresponde a $113,63 \mathrm{~km}^{2}$ ha, área total do Município de Lagoa Seca, PB, circunscrita neste estudo. Os resultados estão apresentados por mapas e valores referentes a áreas correspondentes à cobertura vegetal natural e uso do solo do município de Lagoa Seca, nos anos de 1984 e 2001.

\section{Caracterização da cobertura vegetal natural e uso agrícola do solo}

As fisionomias estão identificadas e descritas segundo terminologias referenciadas pelo Sistema de Classificação Fitogeográfica (FIBGE, 1992, 1999), caracterizadas como capoeirinha, capoeira rala, capoeira e capoeirão, como Sistema Secundário de segunda, terceira, quarta e quinta fases, respectivamente.

Mesmo tipicamente caracterizadas as fisionomias interpretadas, ensejam inclusão de outros tipos de fisionomias, 
não individualizadas ou mapeadas, considerando-se o nível de detalhamento utilizado de 1:30.000, nas fotografias aéreas e 1:100.000 na imagem de satélite.

A interpretação e a análise preliminar foram procedidas com a identificação das fisionomias da vegetação natural mapeadas e informações sobre a ocupação agrícola do solo, segundo as especificações do Sistema de Classificação Fitogeográfica e do Sistema de Classificação de Uso da Terra (FIBGE, 1992, 1999).

\section{A distribuição espacial das fisionomias}

A identificação por fotointerpretação das fotografias aéreas de 1984, caracterizando a cobertura vegetal e o uso do solo agrícola na época, em conjunto com as informações obtidas através da classificação supervisionada da imagem de 1989, sobre os mesmos aspectos, subsidiou a orientação e a identificação dos locais das fisionomias atuais.

Essas informações possibilitaram a confecção do mapa de vegetação e o uso agrícola do solo atual que, por sua vez, subsidiou o estudo da evolução do quadro natural possibilitando o diagnóstico quanto aos diferentes usos verificados.

A individualização espacial e a definição das cores atendem, respectivamente, o Sistema de Classificação Fitogeográfica para o Sistema Secundário e aos Critérios para a Elaboração da Legenda de Uso da Terra (FIBGE; 1992, 1999) e à International Standards Organization. Em virtude de ocuparem áreas restritas e pontuais nas situações observadas para se salientarem melhor, as fisionomias da vegetação natural foram uniformizadas.

As referidas individualização e unificação estão retratadas nos mapas de vegetação e uso agrícola de 1984 e 2001, nas Figuras $1 \mathrm{~A}$ e B.

Os mapas representam um esboço sintético das fisionomias vegetais potenciais identificadas em dois anos, 1984 e 2001, disponibilizando informações para a possível adoção de estratégias que conciliem preservação ecológica com desenvolvimento agrossocioeconômico no município.

As áreas que não têm sua classificação mencionada correspondem a áreas ou situações embutidas na fisionomia predominante em cada situação, visto apresentarem aspectos de exploração agrícola mista ou se constituírem em faixas de transição.

Avaliaram-se as alterações dos espaços ocupados pela vegetação nativa remanescente e pelo uso do solo agrícola, nos dois períodos. A análise visual desse processo evolutivo revelou que houve alterações significativas nas áreas com vegetação natural, principalmente nas situações próximas aos rios e riachos.

Atualmente, essas fisionomias se encontram reduzidas, apresentando-se em forma de pequenas ilhas de vegetação; esta redução se deu, provavelmente, em detrimento do aumento das áreas destinadas à exploração agrícola e, sobretudo, à pecuária, podendo essas alterações ter ocasionado problemas ambientais que, sem dúvida, se desenvolvem na atualidade.

O resgate dessas informações passadas e a comparação com a situação presente, possibilitaram tecer considerações que traduzem a verdadeira caracterização da área estudada.

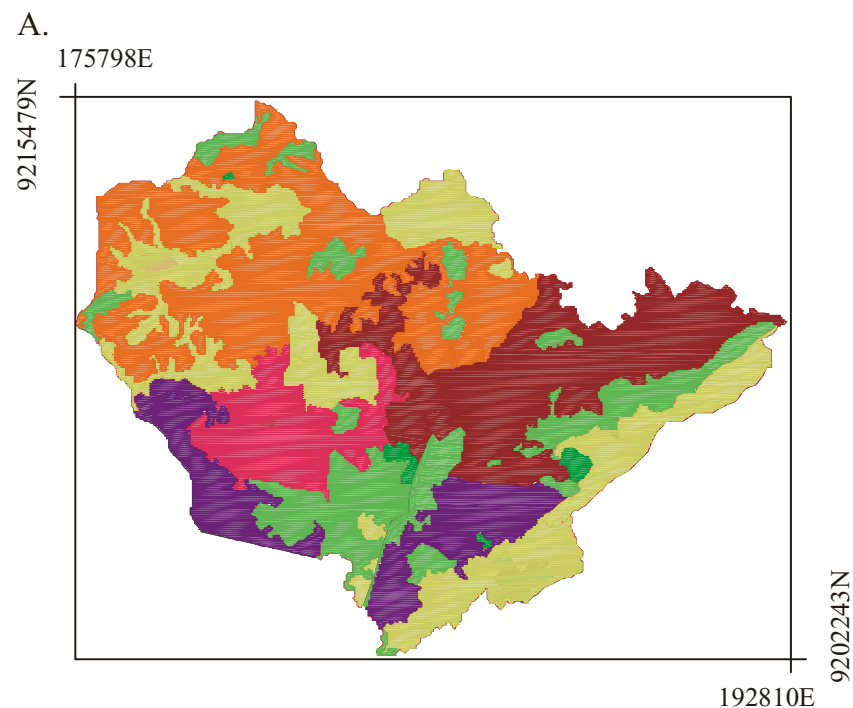

B.
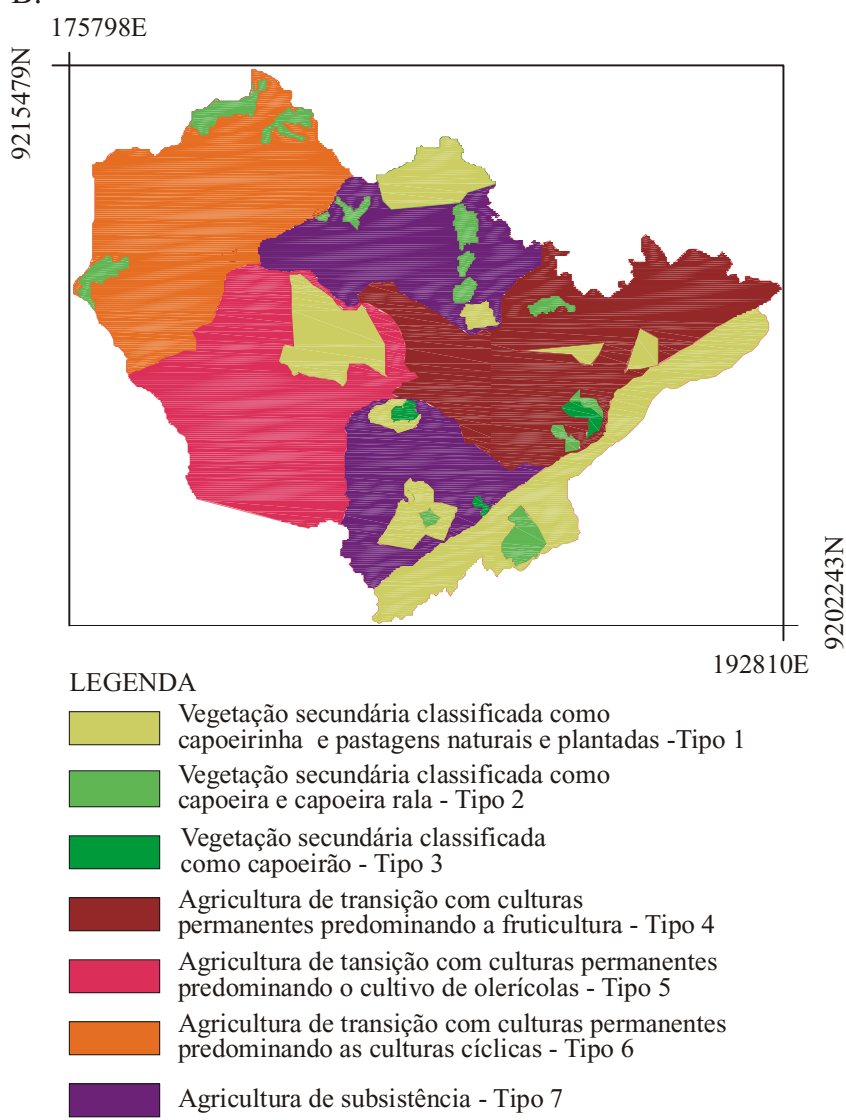

Figura 1. Caracterização da cobertura vegetal e uso agrícola do solo do Município de Lagoa Seca, PB, 1984 (A) e 2001 (B)

As fotografias aéreas e a imagem de satélite são de extrema importância haja vista que é nos registros oficiais que as áreas de cobertura vegetal natural do município podem ser visualizadas e suas delimitações convertidas em forma de mapa.

A mais antiga referência sobre a vegetação natural do município é dada por von Luetzelburg (1923) em estudos botânicos do Nordeste; no entanto, as informações se restringem à menção das espécies existentes na época. Mais 
recentemente, o estudo da realidade do município realizado pela EMATER (2000) cita espécies ainda encontradas na sua área de abrangência. Constatou-se, durante as visitas a campo, que a maioria das espécies citadas nesses estudos ainda se faz a maioria presentes.

A cobertura vegetal do tipo vegetação secundária, classificada como capoeirão, corresponde às áreas ocupadas com remanescentes florestais de mata nativa, constituindo uma forma de capoeirão; é um estágio eminentemente lenhoso, completando a quinta fase da sucessão natural, denunciando a existência de florestas úmidas em períodos passados.

Este aspecto observado está de acordo com a assertiva de Riché et al. (1987) quanto à cobertura vegetal do município ser típica de áreas de contato entre a floresta Atlântica de planície e encosta e a caatinga hiperxerófila, apresentando grande número de elementos de caatinga sob condições climáticas mais atenuadas, confundindo-se com áreas de floresta úmida.

A cobertura vegetal do tipo arbóreo-arbustiva e arbustivo-arbórea, foi coadunada para melhor se salientar; são estágios que apresentam muitas espécies lenhosas, sublenhosas e poucas herbáceas, formando as terceira e quarta fases da sucessão natural.

As pastagens naturais ou plantadas e a vegetação herbácea também se apresentam incorporadas; a vegetação herbácea se refere à denominada capoeirinha, cujo estágio apresenta gramíneas, sublenhosas e lenhosas de porte baixo e constitui a segunda fase da sucessão natural.

A distribuição dos remanescentes da vegetação consiste, atualmente, pequenos maciços não uniformes de capoeirão, capoeira e capoeira rala, na maioria das vezes inexpressivos, na maioria resultam da renovação vegetal natural devido às condições climáticas propicias. As áreas com expressão estão circunscritas no mapa de vegetação e uso do solo agrícola de 2001 e descritas nas fisionomias legendadas.

$\mathrm{O}$ diagnóstico rápido participativo do município de Lagoa Seca, realizado pela Assessoria e Serviços a Projetos em Agricultura Alternativa, delimita e nomeia em agroecossistemas as regiões, segundo o uso do solo no ano de 1997, AS-PTA (1997) mencionando, em linguagem coloquial, as culturas plantadas, não delimitando áreas com vegetação natural.

Em 1984, as áreas com esse tipo de vegetação se assentavam nos mesmos locais; no entanto, com dimensões maiores. Os pequenos maciços correspondentes à vegetação secundária tipo capoeira e capoeira rala, indicam significativa redução, em virtude da ampliação das áreas urbanizadas, a exemplo da estruturação do Bairro Juracy Palhano e a definição dos lotes para chácaras, nas circunvizinhanças da Conceição.

Outra situação em que ocorreu a redução desse tipo de vegetação foi na área que abrange os sítios Cumbe e Jucá do Cumbe. O intrincamento da paisagem indica o alto grau de fragmentação em toda a área.

Os efeitos negativos da fragmentação e do desmatamento sobre a diversidade de espécies não serão, sem dúvida, plenamente compensados no caso de alguma iniciativa de reabilitação, mas a criação e a manutenção de conexões entre os fragmentos podem ser fatores preponderantes para a con- servação de espécies nessa área intensamente fragmentada.

Procedimento idêntico ao da incorporação da vegetação natural foi adotado para identificação das áreas em que a cobertura vegetal predominante é a agricultura, coadunando as áreas onde a agricultura de subsistência é explorada conjuntamente com explorações agrícolas definidas como fruticultura, olericultura e culturas cíclicas.

As fisionomias do uso agrícola apresentam pequenas alterações relativas às situações e abrangências, constatandose uma redução na dimensão das áreas nas quais se exploravam, em 1984, culturas cíclicas, ocorrendo a substituição por agricultura de subsistência.

A exploração da olericultura apresenta maior abrangência, tal como as áreas de exploração com fruticultura.

\section{Estudo comparativo das fisionomias observadas em 1984 e 2001}

Para cada tipo de cobertura vegetal se conferiu a área através do levantamento das coordenadas geográficas, pelo Sistema de Posicionamento Global-GPS; os dados colhidos subsidiaram a análise comparativa das modificações ocorridas na cobertura vegetal no período compreendido entre os anos de 1984 e 2001. Em virtude da cobertura aérea retratada nas ortofotocartas não cobrirem todo o município, ficando a situação leste sem referência, utilizaram-se as informações da imagem de satélite TM/Landsat-5, datadas de 1989, para complementar a identificação em campo dos fragmentos presentes naquela situação geográfica.

Os resultados apresentados na Tabela 1 demonstram as alterações verificadas nas diferentes fisionomias da cobertura vegetal e uso da terra no município de Lagoa Seca, naquele mesmo período.

Tabela 1. Valores absolutos e percentuais das fisionomias presentes no Município de Lagoa Seca, PB, em 1984 e 2001

\begin{tabular}{|c|c|c|c|c|}
\hline \multirow{2}{*}{ Fisionomias } & \multicolumn{2}{|c|}{1984} & \multicolumn{2}{|c|}{2001} \\
\hline & Área (ha) & $\%$ & Área (ha) & $\%$ \\
\hline Vegetação secundária tipo capoeirão & 98,36 & 0,87 & 67,18 & 0,59 \\
\hline $\begin{array}{l}\text { Vegetação secundária tipo capoeira } \\
\text { e capoeira rala }\end{array}$ & $1.928,72$ & 16,97 & 460,15 & 4,05 \\
\hline $\begin{array}{l}\text { Vegetação secundária tipo } \\
\text { capoeirinha e pastagens naturais e } \\
\text { plantadas }\end{array}$ & 2.117,92 & 18,64 & $1.947,42$ & 17,14 \\
\hline $\begin{array}{l}\text { Agricultura de transição com } \\
\text { predomínio de fruticultura }\end{array}$ & $2.216,16$ & 19,50 & $2.338,62$ & 20,58 \\
\hline $\begin{array}{l}\text { Agricultura de transição com } \\
\text { predomínio de olericultura }\end{array}$ & 901,56 & 7,93 & $2.110,07$ & 18,57 \\
\hline $\begin{array}{l}\text { Agricultura de transição com } \\
\text { predomínio de culturas cíclicas }\end{array}$ & $2.913,66$ & 25,64 & $2.258,09$ & 19,87 \\
\hline Agricultura de subsistência & $1.186,96$ & 10,45 & $2.181,78$ & 19,20 \\
\hline TOTAL & $11.363,34$ & 100,00 & $11.363,34$ & 100,00 \\
\hline
\end{tabular}

Com base nos dados obtidos, pode-se afirmar que da área total com vegetação natural no estágio secundário, evidentes em 2001, somente $2,72 \%$ são de capoeirão; $18,59 \%$ estão cobertos por vegetação secundária do tipo capoeira e capoeira rala, ocupando uma área de 460,15 ha; somente 67,18 ha da área total do município estão ocupados com vegetação secundária do tipo capoeirão $(0,59 \%)$. 
As áreas com vegetação secundária do tipo capoeirinha e pastagem natural e plantada, ocupam $1.947,42$ ha, $17,14 \%$ da área total; comparando-se esses valores com os obtidos para o ano de $1984,2.117,92$ ha $(18,64 \%)$, percebe-se um decréscimo de $1,5 \%$. Este fato ocorreu em detrimento da redução de áreas ocupadas com vegetação secundária do tipo capoeirinha, substituída por agricultura, principalmente culturas cíclicas, nas situações próximas aos riachos da bacia do rio Campinote, o que pode ser observado comparando-se os mapas de vegetação e o uso agrícola do solo de 1984 e 2001 e de áreas de pastagem natural.

Ocorreu um aumento das áreas exploradas com pastagem plantada nas situações de relevo mais ondulado em toda a região central e sul do município.

Considerando-se os 11.363,34 ha de superfície total estabelecidos para o município, conclui-se que dos atuais $1.947,42$ ha, $17,14 \%$ cobertos por este tipo de fisionomia, cerca de 802,44 ha, são pastagens plantadas, usados para a exploração pecuária, em comparação com os 298,53 ha, que se salientava em 1984.

Este significativo aumento de áreas exploradas com a pecuária pode ser visto sob dois aspectos: substituição do tipo de exploração pela resposta economicamente positiva nas áreas em que antes se cultivavam culturas comerciais, como a fruticultura e olericultura, e substituição da vegetação tipo capoeira rala por pastagem, devido à possibilidade de um aproveitamento econômico.

A exploração pecuária se evidencia em propriedades de porte médio e grande, nas quais há exploração do gado bovino em sistema semi-extensivo, e em médias e pequenas propriedade,s em que se exploram caprinos e suínos.

As áreas de uso agrícola em que se explora a agricultura de transição com predomínio da fruticultura, correspondem a 2.338,62 ha, 20,58\% da área total do município. Comparando-se a área explorada em 1984, constata-se um acréscimo de $1,08 \%$ na área dessa fisionomia. No uso agrícola do solo direcionado à exploração de frutíferas, as propriedades são, na maioria, de tamanho médio, caracteristicamente familiares.

A área de uso agrícola na qual se explora a agricultura de transição com predomínio de olerícolas, tem superfície de $2.110,07$ ha $(18,57 \%)$. Considerando-se a abrangência dessa fisionomia em 1984, nota-se um acréscimo de $10,64 \%$ na área explorada com esse tipo de agricultura o que se justifica, devido à presença significativa de reservatórios de água, fator essencial a essa exploração agrícola.

A área de abrangência da agricultura de transição com predomínio de culturas cíclicas, tem superfície equivalente a 2.258,09 ha, ou $19,87 \%$ da área total do município; em 1984, esse tipo de uso agrícola do solo ocupava 2.913,66 ha, ou $25,64 \%$ da área total, donde se conclui ter ocorrido um decréscimo de $5,77 \%$ dessas áreas de uso agrícola.

Este fato ocorreu, provavelmente, em detrimento da substituição desse tipo de uso do solo por agricultura de subsistência, fruticultura e pequenos pastos, devido à resposta negativa do solo ou a problemas de comercialização. A exploração agrícola familiar é a forma predominante e se dá em propriedades de médio e pequeno porte.

O uso do solo para exploração de agricultura de subsis- tência abrange $2.181,78$ ha, $19,20 \%$ da área total do município. Comparando-se com os valores obtidos para o ano de $1984,1.186,96$ ha $(10,45 \%)$, constata-se ter ocorrido um acréscimo significativo das situações em que se explora esse tipo de agricultura.

São dois os locais em que esta exploração ocorre atualmente, na porção norte e sudeste do município, em virtude desse tipo de exploração nessas situações ocorrer em detrimento do condicionamento imposto pela topografia mais ondulada, mesmo apresentando áreas de topo plano. O uso agrícola do solo quase que exclusivamente de subsistência, é bastante diversificado com frutíferas e culturas de ciclo curto.

Observado-se a variação dos valores percentuais dos incrementos decorridos das modificações em cada fisionomia no período 1984-2001 na Figura 2, constata-se que:

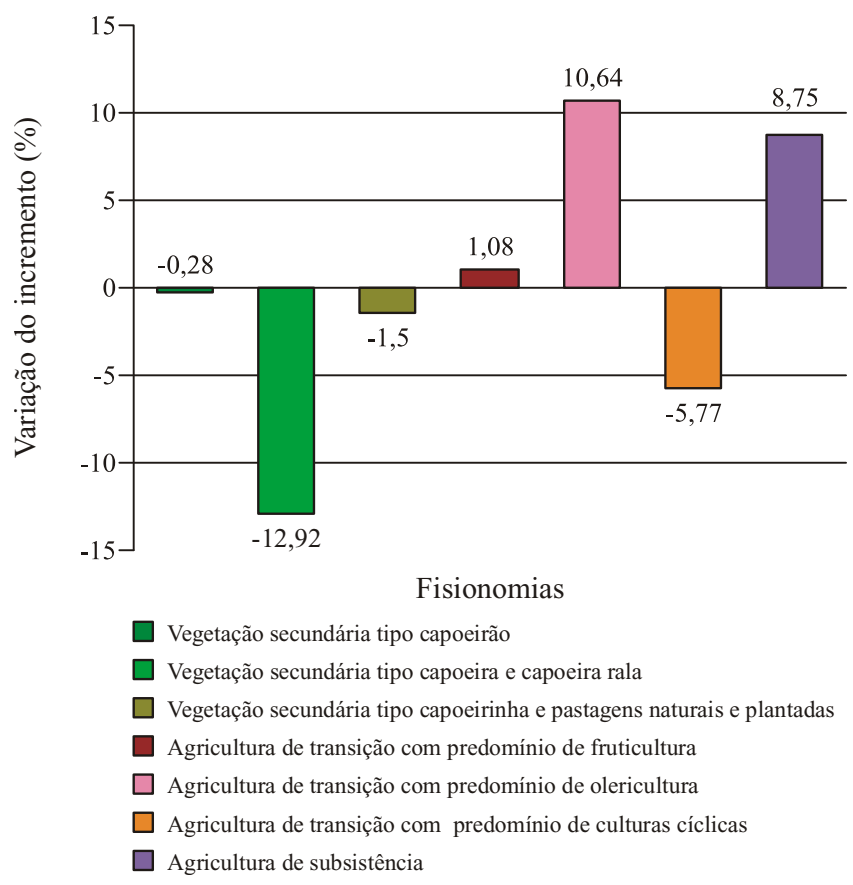

Figura 2. Variação percentual dos incrementos observados para as fisionomias entre os anos de 1984 e 2001

A fisionomia vegetação secundária, classificada como capoeira e capoeira rala, apresentou um incremento negativo de $-12,92 \%$, seguida da fisionomia agricultura de transição com predomínio de culturas cíclicas que, em decorrência da redução da abrangência da área explorada, apresentou incremento negativo de $-5,77$.

A fisionomia vegetação secundária classificada como capoeirinha, pastagens natural e plantada, apresentou um incremento negativo de $-1,50$; tal decréscimo é devido à redução da substituição da vegetação do tipo capoeirinha por outras fisionomias do tipo agricultura de transição e de subsistência, principalmente na porção oeste do município.

A fisionomia vegetação secundária, classificada como capoeirão, indicou um incremento negativo de $-0,28 \%$; as áreas mensuradas estão em propriedades privadas, com proibição de acesso; entretanto, mostrou diminuição da sua área. 
As fisionomias agricultura de transição com predomínio de fruticultura, de olericultura e agricultura de subsistência, apresentaram incrementos positivos, respectivamente, 1,08, 10,64 e $8,75 \%$, salientando-se a olericultura e agricultura de subsistência com os maiores percentuais, correspondendo às fisionomias cujo aumento de áreas de abrangência foi mais significativo.

A situação, aparentemente estável destes modelos de produção agropecuária, não se reflete na dinâmica do uso do solo. A análise dos desmatamentos indica que a substituição da cobertura vegetal por agricultura e pastos plantados é um processo constante.

\section{CONCLUSÕES}

1. Demonstrado o atual cenário de ocupação do solo do município de Lagoa Seca fica evidente que o emprego das tecnologias de SIG é fundamental para o resgate do passado e elaborar o planejamento futuro da paisagem de cada região.

2. Verifica-se que existe um forte processo de alteração da paisagem na região analisada sendo a atividade agrícola a maior responsável pela abertura das novas áreas, pois, os cálculos demonstraram que o município perdeu cerca de $40,23 \%$ de sua vegetação natural no intervalo de anos considerado, isto significa, que com o atual padrão de utilização do solo o município perderá toda sua vegetação natural.

3. Constatou-se uma diminuição das áreas de vegetação nativa nas quatro fases do sistema secundário identificado, salientando-se a fisionomia vegetação secundária classificada como capoeira e capoeira rala, com o maior percentual de incremento negativo $(-12,92)$.

4. Verificou-se um aumento significativo das áreas agrícolas nas quais se pratica a agricultura de transição com predomínio da olericultura e agricultura de subsistência que apresentaram, no período estudado, respectivamente, 10,64 e 8,75 de incremento positivo.

5. Nos dois anos estudados as áreas de maior abrangência são aquelas em que se praticam a agricultura de transição com predomínio de culturas cíclicas e fruticultura.

6. Existem, todavia, meios eficientes que colaboram na tomada de decisões para o planejamento de uso do solo.

7. É necessário assumir o compromisso no cumprimento da legislação ambiental pertinente, partindo de resultados concretos, embora ainda não exista uma política eficaz que possibilite conciliar as atividades econômicas desenvolvidas com conservação ambiental.

\section{LITERATURA CITADA}

Andrade, L. A. Classificação ecológica do Estado da Paraíba. Viçosa: UFV, 1995. 157p. Dissertação Mestrado

Argento, M. S. F. Mapeamento geomorfológico. In: Guerra, A. J. T.; Cunha, S. B. (org.) Geomorfologia: uma atualização de bases e conceitos. 2.ed. Rio de Janeiro: Bertrand Brasil, 1995. p.365-390.
AS-PTA - Assessoria e Serviços a Projetos em Agricultura Alternativa/Projeto Paraíba, Diagnóstico rápido participativo dos agroecossistemas de Lagoa Seca, PB. Relatório, Lagoa Seca, 1997. 35p.

Bertoni, J.; Lombardi Neto, F. Conservação do solo. Piracicaba: Livroceres, 1985. 392p.

Brasil. Ministério das Minas e Energia. Folhas SC. 24-25. Aracaju,Recife. Rio de Janeiro: Radambrasil, Levantamento de Recursos Naturais n.30, 1983. 839p.

Crosta, A. P. Processamento digital de imagens de sensoriamento remoto. Campinas: UNICAMP, 1992. 170p.

EMATER - Empresa de Assistência Técnica e Extensão Rural. Estudo da realidade do município. Lagoa Seca: EMATER, $2000.38 \mathrm{p}$.

Estes, J. E.; Mooneyhan, D. W. Of maps and myths. Photogrammetric engineering and remote sensing, v.60, n.5, p.517-524. 1994.

FIBGE - Fundação Instituto Brasileiro de Geografia e Estatística. Manual técnico da vegetação brasileira. Manuais técnicos em geociências, Rio de Janeiro: FIBGE, n.1, 1992. 92p.

FIBGE - Fundação Instituto Brasileiro de Geografia e Estatística. Manual técnico de uso da terra. Manuais técnicos em geociências. Rio de Janeiro: FIBGE, n.7, 1999. 58p.

Freitas Filho, R. M.; Medeiros, S.J . Análise multitemporal da cobertura vegetal em parte da Chapada do Araripe-CE, utilizando técnica de sensoriamento remoto e geoprocessamento. In: Simpósio Brasileiro de Sensoriamento Remoto, 7, 1993, Curitiba. Anais... São José dos Campos: INPE, 1993. v. 2, p.73-80.

FUNDAP - Fundação de Colonização e Desenvolvimento Agrário do Estado da Paraíba / Terrafoto S. A. Obra 473: foto aérea. Escala: 1:30.000. João Pessoa, Fx4, n.5-9, Fx5, n.4-10, Fx6, n.5-9, 1984.

Guimarães, M. Cartografia ambiental da região de Vitória da Conquista, BA. São Paulo: USP-IB-DEG, 1999. 200p. Dissertação Mestrado

INPE - Instituto Nacional de Pesquisas Espaciais. Spring 3.0: Processamento de imagens. Brasil: 1998. Windows 6.0. CD-Rom.

Lins, J. R. P.; Medeiros, A. N. Mapeamento da cobertura florestal nativa lenhosa do Estado da Paraíba. João Pessoa: PNUD/ FAO/IBAMA/Governo da Paraíba, 1994. 44p.

Melo, A. S. T. de Uso do solo e vegetação atual. In: Paraíba, Secretaria de Educação e Cultura e Universidade Federal da Paraíba. Atlas geográfico do Estado da Paraíba. João Pessoa, 1985. p.48-53

Pacheco, A. P.; Ribas, N. de S. Sensoriamento remoto aplicado ao uso da terra. Revista da Comissão Brasileira de Geodésia. http/ /geodesia.ufsc.br/Geodesia-online/arquivo/1998/04/PACHECO HTM. 29 Nov. 1998.

Ribeiro, S. R. A.; Centeno, J. S. Classificação do uso do solo utilizando redes neurais e o algoritmo MAXVER. In: Simpósio Brasileiro de Sensoriamento Remoto, 10, Foz do Iguaçu, Anais... São José dos Campos: INPE, 2001. p.1341-1348.

Riché, R. G.; Folius, G. A.; Mantovani, L. E. Enfoque geo-ambiental e suas aplicações agroecológicas no TSA: O exemplo do Brejo Paraibano,PB. Petrolina: EMBRAPA/CPATSA, 1987. 68p.

Rosa, R. Introdução ao sensoriamento remoto, Uberlândia: UFU, 1990. 109p. 
Santos, A. P.; Novo, E. M.; Lombardo, M. A. Metodologia de interpretação de dados de sensoriamento remoto e aplicações no uso da terra. In: Simpósio Brasileiro de Sensoriamento Remoto, 1, 1981, São José dos Campos. Anais... São José dos Campos: INPE, 1981. p.172-175.

Santos, C. C.; Martins, A. K. O uso do geoprocessamento para delimitar áreas de ocupação dos solos urbanos. A Microbacia do Córrego Machado, Palmas - TO, um estudo de caso. In:
Simpósio Brasileiro de Sensoriamento Remoto, 10, 2001, Foz do Iguaçu. Anais... São José dos Campos: INPE, 2001. P.1163-1169.

SUDENE - Superintendência de Desenvolvimento do Nordeste. Campina Grande. 1 mapa color 60 x $70 \mathrm{~cm}$. Escala 1:100.000, Recife, 1999.

von Luetzelburg, P. Estudo botânico do Nordeste. Rio de Janeiro: IFOCS, n.d. 224p. 